\title{
Cooperação Militar contra o Crime Organizado: Brasil e Paraguai no combate ao narcotráfico $(1988-2017)^{1}$
}

\author{
Military Cooperation against Organized Crime: Brazil and \\ Paraguay in the fight against drug trafficking (1988-2017)
}

\section{Cooperación militar contra la delincuencia organizada: Brasil y Paraguay en la lucha contra el narcotráfico (1988 - 2017)}

\author{
iD Marcos Alan S. V. Ferreira \\ Universidade Federal da Paraíba, João Pessoa, Paraíba, Brasil \\ marcosalan@gmail.com \\ iD Juliana Leite de Medeiros \\ Universidade Federal da Paraíba, João Pessoa, Paraíba, Brasil \\ jumedeiros92@gmail.com
}

Resumo: A ascensão do crime organizado transnacional ao patamar de ameaça à segurança internacional trouxe mudanças significativas às estratégias de combate ao problema pelos Estados. Seu caráter difuso, que vai além das fronteiras estatais, exige a concatenação de esforços estatais para seu enfrentamento, sob pena de restar infrutífera qualquer política nesse sentido. O Brasil e o Paraguai ocupam papel de destaque no desenvolvimento de atividades ilícitas transnacionais no continente sul-americano, existindo entre eles uma dinâmica de complementariedade entre oferta e demanda de produtos e serviços ilegais. A fronteira entre

\footnotetext{
1 Este artigo consolida os resultados de duas pesquisas dos autores: 1) da dissertação “Cooperação bilateral no combate a criminalidade organizada transnacional: uma análise das ações brasileiro-paraguaias nas regiões de fronteira", de Juliana Leite Medeiros e; 2) resultados parciais da pesquisa "Challenges for Peace in Democratic Societies: public security, crime and violence", conduzida por Marcos Alan S. V. Ferreira em parceria com Oliver Richmond (Univ. de Manchester) e financiada pelo Newton Fund (Bolsa no. NMG2R2\100064).
} 
ambos os países corresponde à rota mais tradicional do narcotráfico na América do Sul, razão pela qual Brasil e Paraguai têm reunido esforços para o enfrentamento da questão, inclusive militarmente. O presente artigo busca analisar como se desenvolve a cooperação militar entre o Brasil e o Paraguai para o combate ao tráfico de drogas na fronteira entre ambos os países. Para tanto, faz-se um resgate conceitual do crime organizado transnacional e sua caracterização na fronteira Brasil-Paraguai. Em seguida, observam-se as iniciativas empreendidas na região de fronteira, em termos de cooperação militar, no combate ao narcotráfico.

Palavras-chave: Cooperação Bilateral Militar. Crime organizado transnacional. Fronteira Brasil-Paraguai.

Abstract: The rise of transnational organized crime to the level of threat to international security has brought significant changes to the strategies to combat the problem by states. Its diffuse character requires the concatenation of state efforts for its confrontation that goes beyond the state borders, under penalty of subduing any policy in this sense. Brazil and Paraguay occupy a prominent role in the development of illegal transnational activities in the South American continent, and there is a dynamic of complementarity between supply and demand of illegal products and services. The border between the two countries corresponds to the more traditional route of drug traffic in South America, which is the reason why Brazil and Paraguay have joined efforts to address the issue, including militarily. This article aims to analyze how military cooperation between Brazil and Paraguay develops to combat drug traffic at the border between both countries. For that, a conceptual rescue of the transnational organized crime and its characterization in the Brazil-Paraguay border is made. Initiatives undertaken in the border region, in terms of military cooperation, in combating cross-border crime were observed.

Keywords: Bilateral Military Cooperation. Transnational organized crime. Brazil-Paraguay border. 
Resumen: El aumento de la delincuencia organizada transnacional al nivel de amenaza para la seguridad internacional ha traído cambios significativos a las estrategias de los Estados para combatir el problema. Su carácter difuso requiere la concatenación de los esfuerzos estatales para que su confrontación va más allá de las fronteras estatales, bajo la pena de restar infructuosa cualquier política en esta dirección. Brasil y Paraguay desempeñan un destacado papel en el desarrollo de actividades transnacionales ilegales en el continente sudamericano y hay una dinámica de complementariedad entre la oferta y la demanda de productos y servicios ilegales. La frontera entre ambos países corresponde a la ruta más tradicional del narcotráfico en América del Sur, por lo que Brasil y Paraguay han unido esfuerzos para abordar el problema, incluso a nivel militar. Este artículo pretende analizar cómo se desarrolla la cooperación militar entre Brasil y Paraguay para combatir el narcotráfico en la frontera entre esos dos países. Por lo tanto, se realiza un rescate conceptual de la delincuencia organizada transnacional y su caracterización en la frontera Brasil-Paraguay. A continuación, se presentan las iniciativas emprendidas en la región fronteriza, en términos de cooperación militar, en la lucha contra el narcotráfico. Palabras clave: Cooperación militar bilateral. Delincuencia organizada transnacional. Frontera Brasil-Paraguay.

Data de recebimento do artigo: 06/02/2019

Data de aprovação do artigo: 10/06/2019 


\section{Introdução}

A discussão referente à criminalidade organizada transnacional é tema que vem ganhando destaque na comunidade acadêmica e nas Relações Internacionais em razão da potencialidade lesiva que esse tipo de empreendimento apresenta para economias nacionais, mercados financeiros e sociedade civil de uma forma geral (CAPIE, 2016; ZABYELINA, 2009). No pós-Guerra Fria, a aceleração da abertura do mercado financeiro e a facilitação da mobilidade de capital ao redor do globo, aliadas ao fluxo de pessoas, bens e serviços cada vez maior entre os Estados deu margem a vários efeitos, tanto positivos quanto negativos. Nesse último caso, construiu-se o espaço propício ao nascimento de uma criminalidade organizada de caráter transnacional, cada vez mais poderosa: uma verdadeira ameaça à soberania estatal e ao seu desenvolvimento econômico e social (CASTELLS, 2010; NAIM, 2006).

O Brasil sofre diretamente com as consequências trágicas ocasionadas pela ameaça do crime organizado, cuja gravidade é potencializada quando conjugada às violências estruturais tão presentes em nosso cotidiano, geradas pela pobreza, marginalização, degradação ambiental e violações a direitos humanos básicos (FERREIRA, 2017b). A situação se torna mais flagrante em significativa parte da faixa fronteiriça do país, em áreas caracterizadas, dentre outros aspectos, pelo controle estatal ainda deficitário e pela atuação mais livre e incisiva de grupos criminosos².

Considerando o caráter transnacional do problema, a cooperação internacional tem sido vista como um imperativo para um sucesso mais duradouro das estratégias de enfrentamento desse desafio (NAIM, 2006). O Brasil tem se destacado nesse aspecto na América do Sul nos últimos vinte anos e vem promovendo acordos de cooperação para combate ao crime organizado com seus vizinhos. Todavia, incapaz de dar conta da imensidão do problema por meio dos esforços policiais, o Estado brasileiro (assim como

2 Cabe salientar, porém, que nem toda a área de fronteira sofre destes problemas sociais estruturais. Para mais sobre casos de fronteiras mais pacificadas e integradas, ver Bento (2015). 
Cooperação Militar contra o Crime Organizado: Brasil e Paraguai no combate... Marcos Alan S. V. Ferreira • Juliana Leite de Medeiros

outros da região) tem recorrido cada vez mais às Forças Armadas para contenção da criminalidade organizada transfronteiriça.

Assim sendo, para fins do presente artigo, elegemos a fronteira entre o Brasil e o Paraguai como objeto de estudo. Na fronteira entre esses dois países, que se estende pelos estados do Mato Grosso do Sul (MS) e do Paraná (PR), se encontram as rotas mais tradicionais do tráfico de drogas, de armas e de contrabando no país (ALMEIDA, et al., 2017). É também nessa região que se situam duas importantes zonas de fronteira do país, que são aquelas estabelecidas entre as cidades gêmeas de Foz do Iguaçu (PR)/Ciudad del Este (PY) e Ponta Porã (MS)/Pedro Juan Caballero (PY).

Esta investigação fundamentada em fontes primárias - majoritariamente do governo brasileiro e das Nações Unidas e na literatura especializada - centra-se no seguinte questionamento: como se desenvolve a cooperação militar entre o Brasil e o Paraguai para o combate ao tráfico de drogas na fronteira entre ambos os países? Objetiva-se, assim, descrever como Brasil e Paraguai têm atuado conjuntamente em relação ao problema do narcotráfico na região de fronteira compartilhada, em termos de cooperação militar, no período compreendido entre 1988 e 2017.

Para tanto, adota-se o método analítico-descritivo, por meio da abordagem qualitativa. Os documentos analisados consistem nos instrumentos de cooperação firmados bilateralmente entre Brasil e Paraguai que orbitam ao redor do combate ao crime organizado no que diz respeito ao narcotráfico. Tais documentos foram extraídos do sistema Concórdia, base de dados de atos internacionais do Brasil mantida pelo Ministério das Relações Exteriores. Adicionalmente, entrevistas semiestruturadas com oficiais de segurança atuando em fronteiras brasileiras complementaram uma melhor análise dos dados coletados.

A escolha do ano de 1988 como marco temporal dá-se em razão da assinatura do Acordo sobre Prevenção, Controle, Fiscalização e Repressão ao Uso Indevido e ao Tráfico llícito de Entorpecentes e de Substâncias Psicotrópicas, origem do comprometimento de 
Cooperação Militar contra o Crime Organizado: Brasil e Paraguai no combate... Marcos Alan S. V. Ferreira • Juliana Leite de Medeiros

ambos os países no empreendimento de esforços conjuntos para a realização de programas específicos de controle, fiscalização e repressão ao tráfico ilícito de drogas.

O texto encontra-se disposto em três seções. Na primeira delas, faz-se uma breve análise do fenômeno da criminalidade internacional, seu crescimento após a Guerra Fria e ascensão ao status de nova ameaça à segurança internacional. Posteriormente, é feito um trabalho de caracterização da região de fronteira entre o Brasil e o Paraguai. Na última seção, tratar-se-á da cooperação firmada entre o Brasil e o Paraguai, notadamente a cooperação militar.

\section{Crime organizado transnacional: uma nova ameaça?}

A atuação transnacional do crime organizado não é essencialmente uma novidade na história, estando profundamente enraizada em várias culturas e em um contínuo processo de evolução de acordo com as mudanças políticas, sociais e econômicas (OBOKATA, 2010). Entretanto, mudanças significativas tiveram lugar no mundo entre o fim dos anos 1980 e começo dos anos 1990, e o fenômeno do crime organizado, acompanhando o fluxo dessas transformações, ampliou suas atividades dentro do plano internacional e reorganizou-se estruturalmente, tornando-se mais eficiente e lucrativo.

A nova estruturação das organizações criminosas inaugurou uma nova forma de análise e enfrentamento do fenômeno. A proposta conceitual inserida na noção de "novas ameaças" possibilita, por um lado, avaliar o novo modelo de crime organizado - um ator não-estatal - como uma fonte legítima de insegurança aos Estados e à sociedade e, por outro, discuti-lo como agente promotor de conflitos com impactos relevantes no âmbito internacional e que requer novas formas de cooperação entre Estados, governos subnacionais e atores não-estatais (HERZ, 2010). 


\section{Conceito de crime organizado transnacional}

A despeito de seus mais variados efeitos nos âmbitos social, político e cultural, é na ordem econômica que o fenômeno da globalização se revela mais contundente, em especial com uma maior interligação de mercados nacionais por meio da remoção dos entraves existentes à livre circulação de bens, capitais e serviços. Dessa forma, seria possível conceber uma economia global, integrada e interdependente, caracterizada pela dispersão da produção e do consumo global, pela sofisticação do mercado financeiro - cada vez mais ágil, volátil e especulativo, e pelos avanços tecnológicos nas áreas relativas ao processamento, difusão e transmissão de informações (CASTELLS, 2005; vide também CAPIE, 2016; ZABYELINA, 2009).

É nessa realidade de relativização de fronteiras nacionais e facilidade de intercâmbio de bens e fluxo de capitais que se revela uma dos múltiplos efeitos colaterais do processo de globalização, notadamente no âmbito econômico: o desenvolvimento de uma nova criminalidade organizada, de caráter transnacional, adaptada à nova lógica de mercado, tendo adotado um caráter empresarial similar a tantos outros empreendimentos lícitos ${ }^{3}$. (WILLIAMS, 2001).

O crime organizado global tornou-se um gigantesco fenômeno de caráter delituoso, operacionalizando segundo estratégias em rede. [...] tornou-se uma dinâmica e complexa estrutura financeira global, caracterizando-se pela diversidade, amplitude, adaptação ao ambiente e se reestruturando de acordo com a evolução das técnicas (VIEIRA; VIEIRA, 2007, p. 48-49).

A representação da força econômica em que se traduz o crime organizado transnacional pode ser encontrada na alta lucratividade que detém essa economia ilícita. Segundo o Escritório das

3 Nesse sentido, Williams (2001, p. 106) compreende o crime organizado como extensão do comércio, por meios ilícitos. Para o autor, as organizações criminosas transnacionais funcionam como as contrapartes ilícitas das multinacionais. 
Cooperação Militar contra o Crime Organizado: Brasil e Paraguai no combate... Marcos Alan S. V. Ferreira • Juliana Leite de Medeiros

Nações Unidas sobre Drogas e Crime (UNODC), o crime organizado transnacional apresentou ganhos estimados em 870 bilhões de dólares ao ano, receita equivalente a 1,5\% do PIB mundial e a 7\% das exportações mundiais de mercadorias ${ }^{4}$.

O crime organizado transnacional tem se configurado uma séria ameaça à governança e à estabilidade dos Estados ao explorar indivíduos e submeter significativa parcela da população à violência física e estrutural. O crime alimenta a corrupção e se infiltra nos negócios e na política, minando a governança estatal e dificultando o desenvolvimento (UNODC, 2010). Trata-se de um problema global que enfraquece os Estados nacionais, corrompe suas instituições e acarreta graves prejuízos à ordem econômica e social (FERREIRA, 2019).

O crime organizado tem, ainda, forte ligação com problemas sociais, tais como pobreza, exclusão social e altos índices de violência ao redor do globo, fontes de violência estrutural que alimentam o crime organizado e são por ele fomentados na mesma medida (FERREIRA, 2017b; BLACKWELL; DUARTE, 2014). Nesse sentido, preciso é o entendimento de Ferreira (2017b, p. 41) ao destacar que "o crime organizado usa a estrutura de desigualdade que se manifesta como violência estrutural para parte da população, e simultaneamente reproduz essa estrutura violenta".

Nesse contexto, considerando a realidade latino-americana, Blackwell e Duarte (2014, p. 111) asseveram que muitas atividades criminosas e muitos problemas de violência presentes na região, a exemplo do alto número de homicídios e de população carcerária, estão ligados à exclusão social, que se torna uma forma de violência estrutural e cultural que impede o desenvolvimento pleno das pessoas, especialmente os grupos socialmente vulneráveis, tais como mulheres e jovens.

Quanto ao conceito de crime organizado (ou a lista de crimes que o compõe), não existe consenso entre os estudiosos da área, tampouco entre os Estados. A ONU, por meio da Convenção con-

4 Cf. Crime organizado transnacional gera 870 bilhões de dólares por ano, alerta campanha do UNODC. Disponível em: https:// nacoesunidas.org/crime-organizado-transnacional-gera-870-bilhoes-de-dolares-por-ano-alerta-campanha-do-unodc. 
Cooperação Militar contra o Crime Organizado: Brasil e Paraguai no combate... Marcos Alan S. V. Ferreira • Juliana Leite de Medeiros

tra o Crime Organizado, de novembro de 2000, tentou resolver o impasse ao estipular, em seu art. $2^{\circ}$, que a criminalidade organizada consistiria num "grupo estruturado de três ou mais pessoas, existente há algum tempo e atuando concertadamente com o propósito de cometer uma ou mais infrações graves ou enunciadas na presente Convenção, com a intenção de obter, direta ou indiretamente, um benefício econômico ou outro benefício material".

Por meio dessa Convenção, a ONU tentou não só construir uma definição comum ao tema, como também buscou precisar as forças que deveriam assumir o seu combate. Em ambos os casos, a proposta está longe de ser uma unanimidade e é alvo de críticas constantes devido "à sua subjacente moral universalista, à sua incapacidade de abarcar as especificidades locais e regionais da criminalidade, bem como à desconsideração das ambiguidades entre o lícito e o legítimo, além de sua pretensão apolítica e incontestável" (PEREIRA, 2013, p. 3). Além disso, a noção ofertada pela Convenção carece de clareza e objetividade quanto aos elementos conceituais, o que abre ensejo para que a interiorização dessas ideias seja feita de maneira distinta por cada Estado.

Os esforços empreendidos pela Convenção contra o Crime Organizado são bastante válidos, ainda que considerados vagos e abrangentes. A Convenção é, indiscutivelmente, um marco na discussão do tema e tem um papel importante no reconhecimento do crime organizado transnacional como um tema tanto de segurança doméstica como de segurança internacional, o que já representa um avanço nessa discussão, não obstante sua fragilidade em termos de compliance por parte dos países.

\section{Segurança internacional, novas ameaças e a demanda por uma nova cooperação}

Com o fim da Guerra Fria, o cenário internacional passa por mudanças significativas, no qual a emergência de novos atores 
Cooperação Militar contra o Crime Organizado: Brasil e Paraguai no combate... Marcos Alan S. V. Ferreira • Juliana Leite de Medeiros

internacionais e de novas dinâmicas regionais fazem despontar correntes teóricas que redefinem os limites dos estudos de segurança, de modo a abranger essa nova realidade do sistema internacional ${ }^{5}$. Dentre essas novas vertentes, merece destaque a Escola de Copenhague, cuja perspectiva teórica sustenta a necessidade de ampliação da agenda de segurança internacional, levando-a além das questões meramente militares, passando a admitir que as ameaças à segurança também poderiam se originar das esferas política, econômica, ambiental e societal (BUZAN, 1991; TANNO, 2003).

A partir dessa nova perspectiva de segurança, a própria percepção do que viria a ser uma ameaça ganha novos contornos. Segundo o relatório $A$ more secure world: Our shared responsibility (ONU, 2004, p. 2), ameaça pode ser entendida como "qualquer evento ou processo que conduza à morte em larga escala ou à diminuição das chances de vida e mina os Estados como unidade básica do sistema internacional". ${ }^{6}$

Diferentes organizações internacionais e Estados nacionais têm distintas percepções de ameaça, tendo em vista tratar-se de uma construção social intersubjetiva. A Organização dos Estados Americanos (OEA), por exemplo, reconhece as diferentes perspectivas de cada Estado do Hemisfério quanto às ameaças e às prioridades em sua segurança, uma vez que estas estão relacionadas às particularidades de cada sub-região e de cada ente estatal. Ainda assim, apresenta um rol similar àquele trazido pela ONU - e ao mesmo tempo mais abrangente - que abarca desde a pobreza extrema e a exclusão social, passando pela deterioração do meio ambiente, pela segurança cibernética, até o crime organizado transnacional e o terrorismo.

De maneira geral, essas novas ameaças diferem-se das tradicionais por seu caráter complexo, interligado, que ultrapassam as fronteiras nacionais e impactam os Estados de maneira difusa, numa dinâmica e intensidade distintas em cada região do globo. Representam, assim, uma nova ordem de desafios de segurança

5 Realidade marcada por uma sensível diminuição dos conflitos interestatais (ONU, 2004).

6 No original: "any event or process that leads to large-scale death or lessening of life chances and undermines States as the basic unit of the international system". 
Cooperação Militar contra o Crime Organizado: Brasil e Paraguai no combate... Marcos Alan S. V. Ferreira • Juliana Leite de Medeiros

aos Estados ao exigir uma lógica de combate que não pode ficar adstrita à força militar (COSSUL, 2014).

Essa ideia é reiterada pela Declaração sobre Segurança nas Américas, promulgada em outubro de 2003 pela OEA, ao asseverar que "as novas ameaças, preocupações e outros desafios à segurança hemisférica são problemas intersetoriais que requerem respostas de aspectos múltiplos por parte de diversas organizações nacionais e, em alguns casos, associações entre os governos, o setor privado e a sociedade civil [...]" (OEA, 2003, p. 4), atingindo de forma diferente cada um dos Estados do Hemisfério.

Ainda que sua atuação seja antiga, o crime organizado transnacional - com sua rede difusa de operação e fomentado pelo processo globalizatório - figura no rol das novas ameaças por atentar contra a paz e contra a segurança internacional, contribuindo para o enfraquecimento do Estado, impedindo o crescimento da economia e debilitando a própria democracia.

Na realidade da América do Sul, região rotulada como uma zona de paz por ser livre de conflitos interestatais (HERZ, 2010; KACOWICZ, 2018), o crime organizado transnacional tem grande participação nos altos índices de violência do continente, responsável por classificar a região como uma das mais violentas do planeta (FERREIRA, 2017a). No caso brasileiro, país com uma das maiores faixas fronteiriças do mundo, existe grande dificuldade em conter o avanço da criminalidade organizada nessas áreas, o que tem dado ensejo a inúmeras iniciativas de cooperação com os países vizinhos nos locais considerados mais preocupantes. Um desses pontos críticos é a fronteira com o Paraguai.

\section{Criminalidade e a fronteira entre o Brasil e o Paraguai}

Historicamente, as relações diplomáticas entre Brasil e Paraguai são consideradas amistosas, tendo sido de fato iniciadas

7 Para a ONU, o crime organizado alimenta inúmeras guerras civis através do comércio ilegal de armas e produtos bélicos, prejudicando os esforços de consolidação da paz em diversas regiões. (ONU, 2004). 
Cooperação Militar contra o Crime Organizado: Brasil e Paraguai no combate... Marcos Alan S. V. Ferreira • Juliana Leite de Medeiros

na época do Primeiro Reinado (1822-1831). Em termos de fronteira, desde 1850 os dois países mantêm acordos bilaterais de livre circulação fluvial no rio Paraguai, que faz a divisa entre eles. O cenário sofreu mudanças com a deflagração da Guerra do Paraguai (1864-1870) e só foi começar a se restabelecer em 1872, com a assinatura dos Tratados de Limites (OLIVEIRA, 2008). Nos anos recentes, a cooperação se intensificou, especialmente durante os governos militares, com a assinatura do acordo para a construção da usina de Itaipu e, mais recentemente, nos governos de Lula da Silva e Dilma Rousseff8.

Em um contexto de assimetria em termos de desenvolvimento entre o Paraguai e o Brasil, aliada a políticas governamentais de povoamento de fronteira promovidas durante a década de 1950, nascem as zonas de fronteira9 que compartilham ambos os Estados e que revelam, de certa maneira, a dinâmica econômica entre esses dois países. Não obstante, cabe ressaltar, as políticas dos governos militares que conduziram Paraguai e Brasil por significativa parte da segunda metade do século XX pouco fizeram para combater o narcotráfico nas regiões de fronteira.

A melhor representação de uma zona de fronteira reside no conceito de cidades-gêmeas (ver BENTO, 2015), que são adensamentos populacionais cortados pela linha de fronteira que apresentam grande potencial de integração econômica e social, a despeito dos limites políticos estabelecidos. No caso da fronteira entre Brasil e Paraguai, destacam-se três pares de cidades-gêmeas: Foz do Iguaçu (PR) e Ciudad del Este (PY), Guaíra (PR) e Salto del Guaíra (PY) e Ponta Porã (MS) e Pedro Juan Caballero (PY). ${ }^{10}$

\footnotetext{
8 Para mais detalhes sobre o histórico recente de uma cooperação mais ampla entre Brasil e Paraguai, recomenda-se a cuidadosa análise de ESPÓSITO NETO e PAULA (2015).

9 Os limites de um território correspondem ao limite jurídico estatal, criado e mantido pelo governo central, constituído como um obstáculo fixo a dividir unidades políticas soberanas - um fator de separação - independentemente dos elementos comuns que eventualmente conectem os territórios divididos. A fronteira, por seu turno, traz uma noção mais profunda e ampla, consistente, sobretudo, em um espaço social e historicamente construído. Distingue-se por ser um fator de integração, na medida em que representa uma "zona de interpenetração mútua, de constante manipulação de estruturas sociais, políticas e culturais distintas". (MACHADO, 1998, p. 42). A ideia abstrata de fronteira se materializa, em termos práticos, dentro da concepção de zona de fronteira, assim concebido o espaço territorial representado pela "união entre as fronteiras de dois ou mais países" que se caracterizam pelas "relações e interações internacionais de ordem econômica, social e cultural" (SILVA, 2011, p. 32), estabelecendo, assim, vínculos e dinâmicas próprias.

10 Recentemente, por meio da Portaria $n^{\circ} 213$, do Ministério da Integração Nacional, de 19.07.2016, mais cinco municípios brasileiros foram definidos como cidades-gêmeas na fronteira com o Paraguai. Destaque para o município de Mundo Novo (MS), que forma fronteira tríplice com Guaíra (PR) e Salto del Guaíra (PY).
} 
Cooperação Militar contra o Crime Organizado: Brasil e Paraguai no combate... Marcos Alan S. V. Ferreira • Juliana Leite de Medeiros

Se, por um lado, as cidades-gêmeas são espaços de grande integração econômica, também são regiões representativas dos "problemas característicos da fronteira, que aí adquirem maior densidade" (BRASIL, 2009, p. 28). Segundo o Ministério da Integração (2005), a exploração não-regulamentada de trabalho e o fluxo ilícito de capitais econômicos e financeiros, além do enfraquecimento do comércio legal e sobrecarga dos serviços públicos, são alguns dos problemas mais recorrentes nessa região de fronteira.

Especificamente quanto à fronteira brasileiro-paraguaia, uma particularidade marcante são os altos índices de violência na região, uma fonte constante de preocupação das autoridades locais e nacionais. Segundo dados do relatório Segurança Pública nas Fronteiras (BRASIL, 2016), das 25 cidades da faixa de fronteira brasileira com o maior número de homicídios, sete encontram-se na fronteira entre Brasil e Paraguai. São elas: Foz do Iguaçu, Cascavel, Umuarama, Toledo e Guaíra, no estado do Paraná; e Dourados e Ponta Porã, no estado do Mato Grosso do Sul. Tais números se repetem do lado paraguaio: os cinco departamentos fronteiriços com o Brasil são os que têm as mais altas taxas de mortes violentas por número de habitantes em todo o país, índices similares aos países mais inseguros do continente e mais que o dobro da média nacional paraguaia (INECIP, 2016).

Tais índices de violência estão ligados à atuação do crime organizado transnacional na região: conforme aponta o relatório Segurança Pública nas Fronteiras (BRASIL, 2016), em determinados municípios da fronteira brasileira, a exemplo de Coronel Sapucaia e Ponta Porã (MS) e Foz do Iguaçu e Guaíra (PR) - todas na fronteira com o Paraguai - o crime organizado transnacional aparece mais enraizado e vinculado aos problemas de segurança pública local. Nessas localidades, as dinâmicas violentas entre grupos nacionais, internacionais e transnacionais relacionadas às disputas e negociações inerentes à composição do mercado atacadista de drogas na região e que transitam entre a cooperação comercial e a competição militarizada, provocam impactos substancialmente 
Cooperação Militar contra o Crime Organizado: Brasil e Paraguai no combate... Marcos Alan S. V. Ferreira • Juliana Leite de Medeiros

negativos nas questões de segurança pública na região, gerando altos índices de violência (BRASIL, 2016) ${ }^{11}$.

A extensa e pouco controlada fronteira brasileira e suas características naturais são comumente apontadas como fatores para justificar os desafios do governo brasileiro em manter o controle sobre a região (ALMEIDA, et al., 2017; COSTA, 2017; OLIVEIRA; MARTINS, 2014). O Paraguai, por sua vez, embora possua uma região de fronteira muito menor, padece do mesmo problema brasileiro e também não possui controle efetivo sobre suas fronteiras. Alie-se a isso a natural vulnerabilidade das fronteiras, em comparação com outras partes do território nacional - que aprimora as dinâmicas ilícitas e confere às zonas de fronteira uma posição privilegiada dentro dos mercados ilícitos transnacionais - e tem-se, assim, o espaço propício ao desenvolvimento de empreendimentos criminosos que se valem justamente do controle estatal precário diante de uma fronteira aberta e livre para o fomento de suas atividades ilícitas, notadamente o tráfico de drogas.

Paulo Pereira (2013, p. 8) assevera que Brasil e Paraguai ocupam papel de destaque no desenvolvimento de atividades ilícitas transnacionais no continente e que existe entre eles uma dinâmica de complementariedade entre oferta e demanda de produtos e serviços ilegais: enquanto o Paraguai corresponde a um país de oferta, o Brasil assume o papel de um país de demanda.

É relevante destacar aqui a classificação elaborada por Dreyfus (2009, p. 180), que categoriza as atividades ilícitas como "indústrias ilegais", que contam com alto grau de inovação e empreendedorismo (GOTTSCHALK, 2010). A primeira delas seria a indústria agroexportadora ilegal, responsável por cultivar, colher e distribuir produtos que não ainda não foram processados. O Paraguai sobressai nesse aspecto, sendo o maior produtor de cannabis da América do Sul, segundo a International Narcotics Control Board (2013). Ainda segundo a INCB, "enquanto a cannabis apreendida na Colômbia em 2014 foi cultivada domesticamente, as apreen-

11 Informação corroborada em entrevista. Anônimo - Oficial da Agência Brasileira de Inteligência. Foz do Iguaçu/Brasília (videoconferência), 10 de Janeiro de 2019. Entrevista semiestruturada feita para a pesquisa "Challenges for Peace in Democratic Societies: public security, crime and violence", financiada pelo Newton Fund/British Academy. 
Cooperação Militar contra o Crime Organizado: Brasil e Paraguai no combate... Marcos Alan S. V. Ferreira • Juliana Leite de Medeiros

sões reportadas pelo Brasil foram de cannabis que entraram no país vinda do Paraguai" (INCB, 2016, p. 63), o que só reforça a dinâmica de oferta e demanda proposta por Paulo Pereira (2013).

A segunda categoria seria a indústria ilegal de transformação, que pode envolver tanto um processo de produção e transformação da matéria-prima, como a atividade de agregar valor a um produto já industrializado. É o que acontece com a produção da folha da coca e sua transformação em cocaína, por exemplo (DREYFUS, 2009). Nesse caso, o Paraguai funciona como uma das mais tradicionais rotas de entrada da cocaína vinda dos países produtores, como Bolívia, Colômbia e Peru, em direção à região do Cone Sul, notadamente o Brasil - o maior mercado consumidor do continente. O Brasil, nesse contexto, torna-se também "ponte" entre o produtor da droga e o mercado consumidor de cocaína norte-americano e europeu (UNODC, 2013).

A terceira categoria é a da indústria de proteção ilegal, voltada à proteção armada das demais categorias de "produção industrial", com o uso ilegal da força. Enquadram-se nessa classificação, dentre outros, os grupos de extermínio e as redes de distribuição de armas de fogo e munição. Destaca-se, nesse cenário, o papel do Brasil, seja como rota para outros países, seja como destino final das armas ilegais (BRASIL, 2006). Ademais, essa "indústria" é a grande responsável pelos altos índices de violência que incidem sobre a região, que vivencia números alarmantes de homicídios (PEREIRA, 2013).

Além das dinâmicas de oferta e demanda das drogas e das armas ilícitas, a prática do contrabando e da falsificação de produtos também é uma atividade comum e bastante peculiar da fronteira entre o Paraguai e o Brasil, sendo que o primeiro é um importante fornecedor de produtos, e o último, um mercado consumidor expressivo.

Ao contrário do senso comum, que tende a ver a fronteira entre Foz do Iguaçu (PR) e Ciudad del Este (PY) como a mais importante em termos de contrabando, a principal porta de entrada em território brasileiro de produtos contrabandeados e falsificados está 
Cooperação Militar contra o Crime Organizado: Brasil e Paraguai no combate... Marcos Alan S. V. Ferreira • Juliana Leite de Medeiros

entre as cidades de Ponta Porã (MS) e Pedro Juan Caballero (PY). Dados apurados pelo relatório Segurança Pública nas Fronteiras (BRASIL, 2016) apontam que o maior número de ocorrências de apreensões de contrabando na faixa de fronteira brasileira deu-se na região de Ponta Porã com Foz do Iguaçu, ocupando a quarta colocação. O comércio ilícito transfronteiriço da zona Foz do Iguaçu/ Ciudad del Este, por outro lado, é a principal rota de "contrabando formiga" (RODER, 2005) $)^{12}$.

Outro elemento central neste cenário é a assimetria entre as forças de segurança dos dois países, fato que traz consigo desafios de grande relevância. A capacidade brasileira em termos de recursos humanos e materiais, ainda que insuficiente, é significativamente maior do que a paraguaia. Isso reflete na diferença salarial entre as polícias nacional (Paraguai) e federal (Brasil), o que leva a uma propensão maior de índices de corrupção na polícia paraguaia. Adicionalmente, ainda que a cooperação policial entre ambos os países seja amistosa, a polícia paraguaia tem uma grande dependência da brasileira em termos de transferência de recursos e know-how, especialmente nas buscas, prisões e apreensões conjuntas, que são dependentes de recursos materiais brasileiros ${ }^{13}$.

Para além da cooperação policial, os Estados brasileiro e paraguaio têm se movimentado nos últimos anos em direção à via militar no combate dessa criminalidade que assola sua fronteira compartilhada. Nesse âmbito, a cooperação entre os dois países, nos mais diversos segmentos, tem crescido como alternativa viável e de mais efetividade no combate ao crime organizado transnacional.

\footnotetext{
12 Na definição de Ariane Roder (2005, p. 12), contrabando formiga diz respeito ao "comércio ilícito de pequena escala, geralmente feita por pessoas (nomeadas de mulas) contratadas pela rede organizada do crime para transportar pela fronteira mercadorias de pequeno porte".

13 Informações cedidas em duas entrevistas: 1) Anônimo - Membro da Polícia Federal do Brasil. Foz do Iguaçu, 10 de Janeiro de 2019. Entrevista semiestruturada feita para a pesquisa "Challenges for Peace in Democratic Societies: public security, crime and violence", financiada pelo Newton Fund/British Academy; 2) Anônimo - Oficial da Agência Brasileira de Inteligência. Foz do Iguaçu/Brasília (videoconferência), 10 de Janeiro de 2019. Entrevista semiestruturada feita para a pesquisa "Challenges for Peace in Democratic Societies: public security, crime and violence", financiada pelo Newton Fund/British Academy.
} 


\section{Cooperação militar entre Brasil e Paraguai e o combate ao narcotráfico na fronteira}

Em um contexto de expansão do crime organizado, a atuação estatal não poderia ficar restrita às fronteiras nacionais, sob pena de restar infrutífera qualquer política nesse sentido. Como aponta o Relatório The Globalization of Crime da UNODC (2010, p. 2), "desde que o crime se tornou global, respostas puramente nacionais são inadequadas: elas deslocam o problema de um país para outro". ${ }^{14}$ Emerge, então, a necessidade de internacionalizar o enfrentamento a essa prática delitiva, como forma de tentar conter o avanço do crime transnacional e suas consequências para a segurança dos cidadãos e o desenvolvimento sustentável de economias locais e regionais.

A cooperação internacional torna-se, assim, uma importante ferramenta de fortalecimento da soberania dos Estados e de suas instituições destinadas à prevenção e combate ao crime, bem como da segurança nos planos interno e internacional. Seria o instrumento com maior aptidão a apresentar uma resposta mais eficaz à criminalidade organizada, que cresce na mesma velocidade de expansão dos mercados globais e do avanço tecnológico.

A promoção da cooperação é o objetivo central da Convenção das Nações Unidas contra o Crime Organizado Transnacional, que em seu artigo $1^{\circ}$ assevera categoricamente que "o objetivo da presente Convenção consiste em promover a cooperação para prevenir e combater mais eficazmente a criminalidade organizada transnacional", cooperação que pode ser desenvolvida em diferentes níveis e modalidades. Dentre essas modalidades possíveis de cooperação destaca-se a cooperação de caráter militar.

Tradicionalmente, as Forças Armadas têm como destinação precípua a defesa externa do território perante ameaças infligidas por outros países, tal como concebido no artigo 142 da Constituição

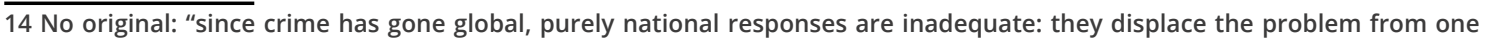
country to another". 
Cooperação Militar contra o Crime Organizado: Brasil e Paraguai no combate... Marcos Alan S. V. Ferreira • Juliana Leite de Medeiros

Federal de 1988. Todavia, o próprio direito brasileiro abre espaço para que as Forças Armadas possam ter atribuições que ultrapassem seu escopo inicial. É o que se vislumbra no artigo 16-A, incluído em 2010 na Lei Complementar n 79/1999, que confere poder de polícia às Forças Armadas na faixa de fronteira terrestre, no mar e nas águas interiores, permitindo sua atuação contra delitos transfronteiriços e ambientais, seja por meio de ações preventivas ou repressivas.

Nas faixas de fronteira caberia às Forças Armadas, portanto, ainda que em caráter subsidiário, a execução de ações de patruIhamento; revista de pessoas, de veículos terrestres, de embarcações e aeronaves; bem como a realização de prisões em flagrante delito. Ao ampliar o escopo de ação das Forças Armadas na região de fronteira, o ordenamento acaba por permitir sua atuação nas duas dimensões de proteção da fronteira interna e externa.

Com o fim da Guerra Fria, que no Brasil coincidiu com o fim do governo militar, o papel das Forças Armadas terminou diminuído. Além dos traumas relacionados à violação de direitos humanos por parte dos militares, reverberou na América Latina o pensamento norte-americano de que as Forças Armadas, finda a grande ameaça do comunismo, deveriam converter-se em força de segurança e, como tal, prestar-se ao combate do narcotráfico, do tráfico de armas e do contrabando (MATHIAS; GUZZI, 2009). Nesse mesmo sentido, Paulo Vizentini (2004, p. 173-174) explicita:

No campo da segurança, foi visível a apresentação de um novo enfoque para as forças armadas. No quadro do pós-Guerra Fria, deveriam ser reduzidas, "profissionalizadas" (isto é, terminar com a conscrição cidadã obrigatória), institucionalizadas em Ministérios da Defesa e destinadas a outras tarefas, como o combate às "novas ameaças" (como o narcotráfico).

Aliada a essa concepção, considerando a realidade brasileira, encontra-se a ideia de que a polícia é corrupta e despreparada e, portanto, incapaz de lidar com a violência crescente, fruto da 
Cooperação Militar contra o Crime Organizado: Brasil e Paraguai no combate... Marcos Alan S. V. Ferreira • Juliana Leite de Medeiros

atuação do crime organizado, o que justificaria o apelo ao uso das Forças Armadas no controle das políticas de combate (MATHIAS; GUZZI, 2009). O Brasil adota, então, o posicionamento de que o tratamento mais adequado aos ilícitos transfronteiriços reside no âmbito da segurança pública, mas que, para alcançar efetivamente a ordem pública nas áreas de fronteira, o apoio das Forças Armadas é fundamental, razão pela qual o país tem se movimentado em direção ao estabelecimento de cooperação militar com os países circunvizinhos.

De modo geral, no âmbito da cooperação em Defesa, o governo Lula da Silva foi profícuo no tocante à quantidade de acordos firmados com diversos países, em relação ao governo anterior e posterior: de 2002 a 2010, foram firmados 16 acordos de cooperação em matéria de defesa e assuntos militares com diferentes países da América do Sul, o que denota a importância do tema na agenda externa brasileira do período (REZENDE, 2015). Tal importância tem estreita ligação com a ideia de que a região tenha autonomia frente a atores externos e evite se converter em um espaço proveitoso ao desenvolvimento e ao fortalecimento das organizações criminosas.

A relação com o Paraguai também foi influenciada por essa perspectiva. O Paraguai é o país que mais tem acordos bilaterais em defesa e assuntos militares com o Brasil, o que expõe a importância do tema para ambos. Dos quatro acordos sobre o tema, firmados pelo Brasil e Paraguaia entre 1988 e 2017 e então vigentes, dois deles foram celebrados durante o governo Lula da Silva.

O intercâmbio militar entre Brasil e Paraguai, no entanto, tem raízes antigas e remonta à década de 1940, quando os primeiros contatos entre os governos paraguaio e brasileiro (comandados, respectivamente, por Higino Morinigo e Getúlio Vargas) deram ensejo à criação, já em 1942, de uma Missão Militar de Ensino, cujo objetivo seria organizar cursos de cavalaria, equitação e educação física - a Missão Militar Brasileira de Instrução no Paraguai (MMBIP), atualmente denominada Cooperação Militar Brasileira no Paraguai (CMPB) (BONDE, 2003). Em razão disso, o Paraguai 
Cooperação Militar contra o Crime Organizado: Brasil e Paraguai no combate... Marcos Alan S. V. Ferreira • Juliana Leite de Medeiros

é o país que mais enviou soldados para treinar junto às Forças Armadas brasileiras: um total de 334 soldados. Em segundo lugar vem a Venezuela, com 281 soldados (REZENDE, 2015).

Essa aproximação entre Brasil e Paraguai para fins militares teve seguimento nas décadas seguintes: ambos os países firmaram entre si acordos para funcionamento de estações de rádio para serviço de assistência a aeronaves militares (1974) e para criação de uma missão técnica da aeronáutica brasileira em Assunção (1982).

O estreitamento dos laços entre os dois países nesse quesito culminou no estabelecimento, em 1995, do Acordo de Cooperação Militar, que substituiu a Missão Militar de Ensino de 1942 (atualmente denominada de Cooperação Militar Brasileira no Paraguai - (MBP) e buscou consolidar, nos termos do acordo, a cooperação dos dois países "com fins científicos, culturais, tecnológicos e de aperfeiçoamento na área militar, a ser canalizada através da Adidância do Exército de sua Embaixada." (BRASIL; PARAGUAI, 1995). O Paraguai é o único país com quem o Brasil já firmou um acordo dessa natureza.

No bojo dessa cooperação militar, Brasil e Paraguai celebraram o Acordo de Cooperação Mútua para Combater o Tráfego de Aeronaves Envolvidas em Atividades llícitas Transnacionais, em fevereiro de 2000, que compreende intercâmbio de informações, treinamento técnico ou operacional especializado, fornecimento de equipamentos e recursos humanos, além da assistência técnica mútua. As ações propostas no âmbito deste acordo representam medidas de enfrentamento ao crime organizado tão presente na região, conduzidas diretamente pelas Forças Armadas (no caso, a Aeronáutica) com vistas a coibir, especialmente, o tráfico de armas, o contrabando e o narcotráfico.

Dentre os acordos mais importantes, destaca-se a assinatura, em 2007, do Acordo Quadro Sobre Cooperação em Matéria de Defesa, um passo importante em termos de cooperação em defesa entre Brasil e Paraguai. O Acordo Quadro mostrou uma incidência muito mais abrangente que a cooperação militar firmada de em 1995 e, dentre outros objetivos, visa a desenvolver uma visão 
Cooperação Militar contra o Crime Organizado: Brasil e Paraguai no combate... Marcos Alan S. V. Ferreira • Juliana Leite de Medeiros

compartilhada de defesa e seus parâmetros comuns com convergência para as doutrinas militares entre ambos os Estados.

Em abril de 2016, o Acordo de Cooperação Militar entre Brasil e Paraguai foi renovado por mais cinco anos, crescendo em importância na agenda bilateral de ambos os países e reafirmando o interesse destes em fomentar exercícios e operações combinadas ou simultâneas na fronteira, capacitação e treinamento, compartilhamento de informações, desenvolvimento de iniciativas para melhor controle do espaço aéreo, dentre outras. A renovação desse acordo veio logo em seguida à definição do compromisso de ampliação da cooperação militar contínua entre os Ministérios de Defesa e Forças Armadas do Brasil e do Paraguai, em janeiro de 2016, para combater grupos do narcotráfico e prevenir o crime na fronteira compartilhada, com o objetivo de salvaguardá-la. Nesse aspecto, o compartilhamento de informações - sempre presente em acordos dessa natureza firmados entre ambos os países - foi eleito como um elemento essencial nessa missão conjunta.

A ampliação concertada pelos governos do Brasil e Paraguai intentava, assim, dar mais visibilidade às novas possibilidades de atuação das Forças Armadas, especialmente no tocante à prevenção e combate à criminalidade organizada transfronteiriça. Em entrevista à Revista Diálogo (2016), o porta-voz das Forças Armadas do Paraguai assevera que os ministros da Defesa do Brasil e do Paraguai:

Concordaram em manter e melhorar os mecanismos de comunicação usados para realizar operações militares na fronteira contra o tráfico de drogas e armas e de todas as atividades criminosas que geram insegurança e preocupação tanto para os dois países quanto para a população civil [...]. Os acordos entre os Ministérios da Defesa são importantes e vitais para continuar o trabalho de cooperação em defesa, que visa a um futuro meIhor para os dois países.

Na ocasião da renovação do Acordo de Cooperação Militar, foi inaugurado o "Mecanismo 2+2 de Consulta Política e Avaliação Estratégica", instrumento pensado para o aprofundamento das re- 
Cooperação Militar contra o Crime Organizado: Brasil e Paraguai no combate... Marcos Alan S. V. Ferreira • Juliana Leite de Medeiros

lações em matéria de política exterior, defesa e segurança entre os dois países sul-americanos. O Mecanismo $2+2$, celebrado em 2007, firma-se como foro diplomático militar dedicado à cooperação bilateral no âmbito de defesa e segurança internacional.

A I Reunião do Mecanismo 2+2 de Consulta e Avaliação Estratégica entre Brasil e Paraguai, realizada em abril de 2016, resultou em uma Declaração Conjunta, que identificou a questão da criminalidade transnacional organizada como um dos grandes problemas a serem enfrentados pelos países nos setores de segurança e defesa. Na oportunidade,

[...] os Ministros concordaram que se poderiam realizar, periodicamente, além do presente Mecanismo 2+2, outras reuniões bilaterais de cunho mais técnico em matéria de defesa, que possibilitem às partes coordenarem-se periodicamente nas áreas de cooperação ou de operações militares, como, por exemplo, exercícios simultâneos ou conjuntos na fronteira, com participação de observadores. Foram abordados, igualmente, temas de cooperação em treinamento, capacitação, compartilhamento de informações, desenvolvimento de iniciativas conjuntas para meIhorar o controle do espaço aéreo, entre outros temas e iniciativas que reforçarão as relações bilaterais nos setores de defesa e segurança (BRASIL, 2016b).

Esse arcabouço de instrumentos cooperativos é o que possibilita uma série de ações militares conjuntas entre Brasil e Paraguai voltadas ao combate ao crime organizado transnacional, ao qual se atribui o status de ameaça à segurança nacional e um problema comum de ambos os países (BRASIL, 2016b). Numa análise breve do teor dos acordos, nota-se que, em essência, nenhum deles faz menção expressa e específica ao uso da força militar no combate ao narcotráfico na fronteira, embora deixe em aberto a possibilidade do estabelecimento de instrumentos cooperativos nesse sentido, tal como aponta o Acordo Quadro Sobre Cooperação em Matéria de Defesa (2007), ao abrir espaço à cooperação na área de defesa em qualquer tema de interesse do Brasil e Paraguai. 
Cooperação Militar contra o Crime Organizado: Brasil e Paraguai no combate... Marcos Alan S. V. Ferreira • Juliana Leite de Medeiros

Já no governo Dilma Rousseff (2011 - 2016), deu-se a criação do Plano Estratégico de Fronteiras (PEF) por meio do Decreto $\mathrm{n}^{\circ}$ 7.496/2011, cuja instituição pretendia o fortalecimento da prevenção, controle, fiscalização e repressão dos delitos praticados na faixa de fronteira brasileira. Pelo PEF pretendia-se, primeiramente, o fortalecimento da prevenção, controle, fiscalização e repressão do crime organizado transnacional atuante na faixa de fronteira brasileira, a partir da efetiva integração das forças de segurança pública e Forças Armadas da União, além da ação dos estados e dos municípios situados na faixa de fronteira (BRASIL, 2011). O PEF foi substituído pelo Programa de Proteção Integrada de Fronteiras (PPIF), já no governo Michel Temer, pelo Decreto $n^{\circ} 8.903$ de novembro de 2016. Ambos os programas comungam, em essência, das mesmas diretrizes: atuação integrada e coordenada dos órgãos de segurança pública, dos órgãos de inteligência, do Ministério da Fazenda, da Receita Federal, do Ministério da Justiça e das Forças Armadas, em concomitância com a cooperação e integração com os países vizinhos.

A edição do PEF foi um marco importante na integração das Forças Armadas na estratégia de combate ao crime organizado transnacional, uma vez que prevê a integração das forças nacionais de segurança pública e das Forças Armadas para essa finalidade (SILVA, 2013). Amparados pelo PEF/PPIF, as Forças Armadas e o Ministério da Defesa vêm assumindo papel mais assertivo no combate ao crime organizado e ao narcotráfico nas áreas de fronteira (MUGGAH; DINIZ, 2013).

\section{Operações militares no combate ao crime organizado}

Das operações que têm sido conduzidas sob orientação do PPIF (e, anteriormente, pelo PEF), destaca-se a Operação Ágata ${ }^{15}$, liderada pelo Ministério da Defesa, por intermédio do Estado-

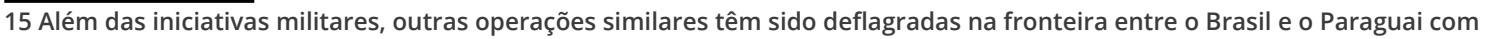
vistas ao combate ao crime organizado na região, tais como a Operação Muralha e a Operação Sentinela, lideradas pela Receita Federal e pela Polícia Federal, respectivamente.
} 
Cooperação Militar contra o Crime Organizado: Brasil e Paraguai no combate... Marcos Alan S. V. Ferreira • Juliana Leite de Medeiros

Maior Conjunto das Forças Armadas (EMCFA). Trata-se de operações combinadas entre Exército, Marinha e Aeronáutica, sob um mesmo comando, tendo como finalidade o fortalecimento da presença estatal na faixa de fronteira do país, assim como o combate a delitos como narcotráfico, contrabando e descaminho, tráfico de armas e munições, crimes ambientais, imigração e garimpo ilegais, dentre outros ilícitos (BRASIL, 2014).

A operação foi elaborada dentro da concepção do Plano Estratégico de Fronteiras [...], cujos principais objetivos são a neutralização do crime organizado, redução dos índices de criminalidade, cooperação com os países fronteiriços e apoio à população de fronteira (BRASIL, 2012, p. 164).

De caráter temporário e atuação episódica, a Operação Ágata abrange ações que envolvem a vigilância e fiscalização do espaço aéreo, bloqueios em rodovias localizadas em pontos estratégicos e operações de patrulha e inspeção nos principais rios e estradas que dão acesso ao país.

A cada Operação os países fronteiriços são convidados a participar, na maioria das vezes, num esquema de cooperação ativa (REZENDE, 2015). Até o presente momento, onze operações Ágata foram realizadas ${ }^{16}$. Dentre elas, sete envolveram trabalhos empreendidos na fronteira entre Brasil e Paraguai - as edições I, III, V, VI, VIII, IX e XI - todas também com alguma participação das Forças Armadas paraguaias, resultado não só da intenção cooperativa do PPIF, mas também dos inúmeros acordos de cooperação firmados entre ambos os países com esse fim. Tais operações foram responsáveis por grandes apreensões de drogas e outros produtos ilícitos.

As Forças Armadas de ambos os países têm colaborado em tais ações, seja com o envio de observadores militares ou reforçando suas fronteiras nos períodos correspondentes às operações, mui-

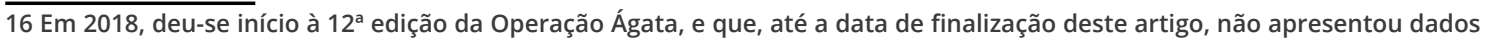
atualizados oficiais das apreensões. 
Cooperação Militar contra o Crime Organizado: Brasil e Paraguai no combate... Marcos Alan S. V. Ferreira • Juliana Leite de Medeiros

tas vezes, assumido o papel de forças policiais, realizando patruIhamento da área e auxiliando nas apreensões e prisões.

Nesse sentido, o país vizinho tem buscado realizar ações semelhantes e simultâneas em seu próprio território, como afirma o ex-ministro da Defesa, Celso Amorim, em entrevista ao Jornal do Brasil (2012). Foi o que ocorreu durante as Operações Ágata 7 e 9, por exemplo, nas quais, nas ações ocorridas nos rios de água compartilhada, o Paraguai realizou a fiscalização nas áreas sob seu domínio, em complemento à fiscalização do lado brasileiro. (DIÁRIO CORUMBAENSE, 2015).

Em entrevista à Revista Diálogo (2016), o Major Brigadeiro Hudson Potiguara, Subchefe da Chefia de Operações Conjuntas do Ministério da Defesa, reafirma a importância do trabalho conjunto com os países fronteiriços em ações deflagradas na fronteira, atribuindo a essa interação o sucesso da estratégia dessas operações. "Se um criminoso passa do Brasil para outro país fugindo da Operação, os militares não podem proceder perseguição ou agir em território vizinho. Mas quando o trabalho é realizado em conjunto, o outro país está em alerta esperando para atuar e colaborar em sua área." (DIÁLOGO, 2016).

Ainda como desdobramento do PEF/PPIF, outro projeto estratégico para o Governo Federal no campo de proteção das fronteiras é o Sistema Integrado de Monitoramento das Fronteiras (SISFRON), capitaneado pelo Exército Brasileiro. Trata-se de sistema de comando e controle, comunicações, computação, inteligência, vigilância e reconhecimento com vistas a conferir uma presença mais efetiva do Exército na faixa de fronteira brasileira e ofertar um fluxo contínuo e seguro de dados dentro das Forças Armadas (LANDIM, 2015). O projeto prevê a ampliação da vigilância nas áreas de fronteira por meio do uso de tecnologias de monitoramento e sensoriamento remoto (SCHERMA, 2016), com o objetivo de auxiliar as forças de segurança que atuam na linha de frente no combate ao crime organizado no controle do narcotráfico e do contrabando na fronteira. 
Cooperação Militar contra o Crime Organizado: Brasil e Paraguai no combate... Marcos Alan S. V. Ferreira • Juliana Leite de Medeiros

Nesse contexto, o SISFRON surge como importante ferramenta da Política Nacional de Defesa, pois ao mesmo tempo em que prioriza a segurança interna e fortalece a defesa territorial junto às fronteiras, permite ser elo entre os países fronteiriços pela possibilidade de compartilhamento de dados e atuações conjuntas contra os diversos ilícitos transfronteiriços (LANDIM, 2015, p. 140).

A partir da análise dos acordos apresentados, nota-se que, apesar de cada um deles prever um leque de diferentes iniciativas, existe uma ênfase em quatro tipos de ações: inteligência, compartilhamento de informações entre instituições de segurança, execução de operações conjuntas e treinamento de pessoal. A congregação dessas ações culmina na execução de grandes operações, de caráter pontual, que por sua vez, evidenciam a centralidade do combate ao narcotráfico na região, em detrimento de outros mercados ilícitos - como o de armas e o de produtos contrabandeados, por exemplo - e o foco no caráter repressor, principalmente de ataque aos produtores e fornecedores de drogas.

Observa-se, ainda, que, embora a aproximação entre ambos os países venha crescendo no decorrer dos anos, especialmente após a redemocratização no fim dos anos de 1980, Brasil e Paraguai ainda caminham a passos lentos quanto ao estabelecimento de políticas públicas comuns voltadas ao enfrentamento dos ilícitos transnacionais, via instrumentos de cooperação internacional. Apesar de terem estreitado os laços de confiança que os unem nas últimas décadas e de serem, inclusive, Estados-parte em vários tratados e acordos que versam sobre o tema, Brasil e Paraguai ainda guardam certo grau de desconfiança em relação ao outro. Nesse sentido, Maurício Costa (2017, p. 48) aponta que:

[...] as megaoperações realizadas pelo Brasil em suas fronteiras e a constante presença das Forças Armadas geram uma assimetria de poder que dificulta a ruptura da desconfiança, pois, durante boa parte da história do Brasil, o país atuou de modo soberanista nas fronteiras sem preocupar-se em desenvolver 
Cooperação Militar contra o Crime Organizado: Brasil e Paraguai no combate... Marcos Alan S. V. Ferreira • Juliana Leite de Medeiros

canais de diálogo e envolvimento do país vizinho em suas ações na fronteira.

Também as assimetrias de interesses entre os dois países incidem como obstáculos à cooperação: enquanto o interesse do Brasil na fronteira direciona-se ao enfrentamento do narcotráfico e de seus crimes conexos, o Paraguai está muito mais preocupado com questões de segurança fundiária e a tensão social ocasionada pelos "brasiguaios". (COSTA, 2017). Ainda segundo forças de segurança brasileira, a corrupção é um grande desafio nessa cooperação, dado que os ganhos econômicos de agentes policiais paraguaios costumam ser maiores quando são coniventes com a criminalidade organizada ligada ao narcotráfico ${ }^{17}$.

\section{Considerações Finais}

A ascensão do fenômeno do crime organizado transnacional ao patamar de nova ameaça à segurança internacional trouxe mudanças na maneira pela qual os atores internacionais se posicionam para combatê-lo. Reconhece-se que não há espaço para desenvolvimento sustentável, exercício de direitos de cidadania e promoção da paz num contexto em que o crime organizado, muitas vezes, se sobrepõe ao próprio Estado e impõe à sociedade seu modo de governança para consecução de suas condutas delituosas. Assim, a cooperação internacional aparece como a alternativa mais viável para conter o avanço do empreendimento criminoso, cuja rede difusa de atuação, marcada por uma lógica empresarial, desafia o Estado e os organismos internacionais a criar novas estratégias de enfrentamento.

O presente artigo dedicou-se à análise da cooperação militar firmada entre o Brasil e o Paraguai para fins de combate ao tráfico

17 Informação cedida em entrevista in loco. Anônimo - Membro da Polícia Federal do Brasil. Foz do Iguaçu, 10 de Janeiro de 2019. Entrevista semiestruturada feita para a pesquisa “Challenges for Peace in Democratic Societies: public security, crime and violence", financiada pelo Newton Fund/British Academy. 
Cooperação Militar contra o Crime Organizado: Brasil e Paraguai no combate... Marcos Alan S. V. Ferreira • Juliana Leite de Medeiros

de drogas na fronteira entre ambos os países, num período compreendido entre os anos de 1988 e 2017. A observação dos acordos estabelecidos entre ambos os países no período, bem como das iniciativas empreendidas na fronteira em termos de cooperação militar, relativas ao combate ao narcotráfico, denotou que a cooperação brasileiro-paraguaia no tema ainda é pouco diversificada, porquanto esteja focada em ações clássicas de controle do crime que acabam reduzidas à promoção de ações pontuais de apreensão e destruição de cultivos de drogas, por exemplo.

Evidenciou-se, ainda, que apesar de parecer um pouco distante da nova concepção de segurança, cuja ideia central prescinde da atuação meramente militar, as Forças Armadas ainda têm presença constante na agenda de segurança brasileira. Igualmente, demonstrou que, apesar de caminhar a passos lentos, a cooperação nesse sentido representa um avanço na luta contra o crime organizado transnacional.

O reconhecimento de ambos os países da necessidade de cooperar para enfrentar o problema comum que os aflige já pode ser considerado um avanço de relevância no tema do combate ao crime, que ainda se encontra muito atrelado às ações estatais meramente centradas no âmbito doméstico. Esse peso estratégico atribuído à cooperação fica claro com a intensificação dos processos em torno da estipulação de novos acordos e da renovação de outros já existentes, especialmente a partir de meados dos anos 2000.

A ampliação do escopo dos acordos militares, que tradicionalmente versam sobre defesa externa de território, para abarcar ações de combate ao crime organizado e ao tráfico de drogas é latente na cooperação entre Brasil e Paraguai. Ambos os países demonstram ser partidários da ideia de que a força militar representa não apenas um complemento à atuação policial, mas um elemento essencial na manutenção da segurança interna e na contenção do crime organizado, especialmente, do tráfico de drogas. 
Cooperação Militar contra o Crime Organizado: Brasil e Paraguai no combate... Marcos Alan S. V. Ferreira • Juliana Leite de Medeiros

A cooperação, no entanto, não se mostra tão simples: as assimetrias de interesses existentes entre o Brasil e Paraguai, aliada a uma histórica e persistente desconfiança mútua, ainda representam grandes entraves à efetivação de políticas públicas unívocas, capazes de dar resposta efetiva ao problema da criminalidade organizada na fronteira.

Essa dificuldade em cooperar reflete na execução de operações militares conjuntas na região de fronteira. O que se percebe é que a tradução do teor dos vários acordos em ações concretas ainda é pontual e incipiente, estando o Brasil ainda muito voltado à promoção de intervenções e operações internas, dispensando as oportunidades de construção de medidas conjuntas para o enfrentamento do problema do tráfico na fronteira. Ao mesmo tempo, para o Paraguai, suas megaoperações são vistas como ações possivelmente intimidadoras e fonte de ainda mais desconfiança. São obstáculos naturais de uma assimetria de atributos nacionais que é difícil de ser superada para um efetivo combate à criminalidade incidente na fronteira.

Dessa forma, tem-se que Brasil e Paraguai ainda têm muito a caminhar quando se trata de cooperação internacional, especialmente àquela voltada ao combate ao tráfico de drogas e ao crime organizado transnacional tão presente em sua fronteira compartilhada. A cooperação militar entre os dois países é um primeiro passo importante para o enfrentamento do problema em si e também para o desenvolvimento de programas de cooperação integradores em prol da segurança regional.

\section{Referências}

AlMEIDA, Letícia Núñez et al. Subsistema fronteiriços do Brasil: mercaDOS ILEGAIS E VIOLÊNCIA. RIO DE JANEIRO: GRAMma, 2017. 
Cooperação Militar contra o Crime Organizado: Brasil e Paraguai no combate... Marcos Alan S. V. Ferreira • Juliana Leite de Medeiros

BONDE, ALdo. EXPERIÊNCIAS NO EXTERIOR: O INTERCÂMBIO MILITAR BRASILEiro com o Paraguai. PADECEME, Rio de Janeiro, N. 6, P. 76-79, 2003. DisPONÍVEL EM: HTTP://PORTAL.ECEME.ENSINO.EB.BR/MEIRAMATTOS/INDEX.PHP/ RMM/Article/ViewFile/480/426. Acesso em: 17 jul. 2019.

BLACKWELL, Adam; DUARTE, Paulina. Violence, Crime and social eXCLUSION. IN: OEA - ORGANIZAÇÃO DOS ESTADOS AMERICANOS. Inequality and Social Inclusion in the Americas: 14 esSAYS. 2. ed. 2014. DISPONÍVEL EM HTTP://WWW.OAS.ORG/DOCS/DESIGUALDAD/LIBRO-DESIGUALDAD-INGLES.PDF.

BraSil. Brasil e Paraguai renovam acordo militar até 2021. Disponível EM: HTTP://WWW.BRASIL.GOV.BR/DEFESA-E-SEGURANCA/2016/04/BRASIL-E-PARAGUAl-RENOVAM-ACORDO-MILITAR-ATE-2021. Acesso EM: 17 JUL. 2019.

BRASil. Decreto n 5.015, de 12 de março de 2004. Promulga A Convenção das Nações Unidas contra o Crime Organizado Transnacional. Diário Oficial da União, Brasília, 20 mal. 2014. Disponível em: hTtP:// WWW.PLANALTO.GOV.BR/CCIVIL_03/_ATO2004-2006/2004/DECRETO/D5015. HTM. ACESSO EM: 17 JUL. 2019.

BRASIL. DeCreto n ${ }^{0}$ 7.496, de 08 de Junho de 2011. Institui o Plano Estratégico de Fronteiras. Diário Oficial da União. Brasília, 09 de jun. 2011. 2011.

BraSil. Ministério da Defesa. Livro Branco de Defesa Nacional. Brasília: 2012. DisPONÍVEL EM: HTTP://WWW.DEFESA.GOV.BR/ARQUIVOS/2012/MES07/ LBDN.PDF. ACESSO EM: 17 JUL. 2019.

BRASIL. Ministério da Defesa. Operação mobiliza 30 mil militares nas fronteiras do Brasil. Brasília, 10 mal. 2014. Disponível em: htTp://wwW. BRASIL.GOV.BR/DEFESA-E-SEGURANCA/2014/05/OPERACAO-MOBILIZA-30-MIL-MILITARES-NAS-FRONTEIRAS-DO-BRASIL. ACESSO EM: 20 JAN. 2019.

BRASIL. Ministério da Integração Nacional. Secretaria de Programas Regionals. Proposta de reestruturação do Programa de Desenvolvimento 
Cooperação Militar contra o Crime Organizado: Brasil e Paraguai no combate... Marcos Alan S. V. Ferreira • Juliana Leite de Medeiros

da Faixa de Fronteira. Brasília: 2005. Disponível em: http://www.mi.gov. BR/WEB/GUEST/COMISSAO-PERMANENTE-PARA-O-DESENVOLVIMENTO-E-A-INTEGRACAO-DA-FAIXA-DE-FronteIRA. AcEsSO EM: 17 JUL. 2019.

BRASil. Ministério da Integração Nacional. Faixa de fronteira. Programa de Promoção do Desenvolvimento da Faixa de Fronteira - PDFF. Brasília, 2009. DISPONÍVEL EM: HTTP://WWW.INTEGRACAO.GOV.BR/CARTILHA-PDFF. ACESSO EM: 17 JUL. 2019.

BRASil. Ministério da Justiça e Cidadania. Secretaria Nacional de Segurança Pública. Segurança Pública nas Fronteiras: Diagnóstico Socioeconômico e Demográfico. Brasília, 2016. Disponível em: htTP:// WWW.RETIS.IGEO.UFRJ.BR/PRODUCAO/DIAGNOSTICO-SOCIOECONOMICO-E-DEMOGRAFICO-DA-FAIXA-DE-FronteIRA/\#.WZMCW9VKJIU. ACESSO EM: 17 fEV. 2019.

BRASil; PARAGUAi. Acordo entre o Governo da República Federativa do Brasil e o Governo da República do Paragual relativo à Cooperação Militar. Assunção, 24 de Julho de 1995. Disponível em: htTps://Concordia. ITAMARATY.gOV.BR/DETAlHAMENTO/4153. Acesso em: 17 Jul. 2019.

BRASIL; PARAGUAi. Acordo de Cooperação Mútua entre o Governo da República Federativa do Brasil e o Governo da República do Paragual para Combater o Tráfego de Aeronaves Envolvidas em Atividades Ilícitas Transnacionais. Brasília, 10 de fEVEREIRO de 2000. Disponível em: htTPS:// CONCORDIA.ITAMARATY.GOV.BR/DETALHAMENTO/4606. ACESSO EM: 17 JUL. 2019.

BraSil. Acordo Quadro sobre Cooperação em Matéria de Defesa entre o Governo da República Federativa do Brasil e o Governo da República do Paragual. Assunção, 21 de maio de 2007. Disponível em: htTps://conCORDIA.ITAMARATY.GOV.BR/DETALHAMENTO/5825. ACESSO EM: 17 JUL. 2019.

Brasil. Declaração que Estabelece o Mecanismo 2+2 de Consulta e Avaliação Estratégica entre o Ministério da Defesa e o Ministério das Relações Exteriores da República Federativa do Brasil e o Ministério de Defesa Nacional e o Ministério das Relações Exteriores da República do 
Cooperação Militar contra o Crime Organizado: Brasil e Paraguai no combate... Marcos Alan S. V. Ferreira • Juliana Leite de Medeiros

Paraguai. Assunção, 21 de maio de 2007. Disponível em: https://concorDiA.ITAMARATY.gOV.br/DEtalhamento/5826. Acesso em: 17 Jul. 2019.

BRASil. Declaração Conjunta adotada por ocasião da I Reunião do Mecanismo 2+2 de Consulta e Avaliação Estratégica entre os Ministérios da Defesa e das Relações Exteriores do Brasil e do Paragual. AsSUnção, 04 dE ABRIL DE 2016. DisPonível EM: HTTP://WWW.ITAMARATY.GOV. BR/PT-BR/NOTAS-A-IMPRENSA/13727-DECLARACAO-CONJUNTA-ADOTADA-POR-OCASIAO-DA-I-REUNIAO-DO-MECANISMO-2-2-DE-CONSULTA-E-AVALIACAO-ESTRATEGICA-ENTRE-OS-MINISTERIOS-DA-DEFESA-E-DAS-RELACOES-EXTERIORES-DO-BRASIL-E-DO-PARAGUAI. ACESSO EM: 17 JUL. 2019.

Bento, Fábio Régio. O Papel das Cidades-Gêmeas de Fronteira na Integração Regional Sul-Americana, Conjuntura Austral, v. 6, N. 27-28, P. 40-53, 2015.

BuZan, Barry. People, States and Fear: An Agenda for International Security Studies in the Post-Cold War Era. New York: Harvester WHEATSHEAF, 1991.

CAPIE, David. Transnational Crime. In: CABAllero-Anthony, Mely. An Introduction to Non-Traditional Security Studies: a transnational APPROACH. LONDRES: SAGE, 2016.

CAStells, Manuel. A Sociedade em Rede. vol.1. 8 ed. São Paulo: Paz e TERRA, 2005.

CAStells, Manuel. End of Millennium. vol.3. 2 ed. New York : WileyBLACKWELL, 2010.

COSSUL, NaIANE Inez. Tráfico Internacional de ARMAS na frontelRa Brasil/Bolívia: dinÂmicas da InSEgURANÇA naCIONAL. $2^{\circ}$ SeminÁRIO de


de Relações Internacionais. JoÃo Pessoa: 2014.

COSta, Maurício Kenyatta Barros da Costa. Políticas de Segurança e Defesa da Fronteira Brasileira no Contexto de Integração Regional: os 
Cooperação Militar contra o Crime Organizado: Brasil e Paraguai no combate... Marcos Alan S. V. Ferreira • Juliana Leite de Medeiros

CAsos das fronteiras Brasil-Paragual e Brasil-Urugual. 211 F. Dissertação (Mestrado em Relações Internacionais). Universidade de Brasílı - UnB, 2017.

DiÁlogo. Brasil e Paragual reforçam a cooperação militar na frontelRA ENTRE OS DOIS PAÍSES. 16 FEV. 2016. DISPONÍVEL EM: HTTPS://DIALOGO-AMERICAS.COM/PT/ARTICLES/BRASIL-E-PARAGUAI-REFORCAM-COOPERACAO-MILITAR-NA-FRONTEIRA-ENTRE-OS-DOIS-PAISES. ACESSO EM: 20 JAN. 2019.

DiÁlogo. Brasil promove nova edição da Operação Ágata. 15 Jul. 2016. DISPONIVEL EM: HTTPS://DIALOGO-AMERICAS.COM/PT/ARTICLES/BRAZIL-PROMOTES-NEW-PHASE-OPERATION-AgATA. ACESSO EM: 07 mal. 2018.

DIÁRIO CORUMBAENSE. Operação Ágata 9 é deflagrada na fronteira com Bolívia e Paraguai. Corumbá, 22 jul. 2015. Disponível em: htTP://diaRIONLINE.COM.BR/?s=NOTICIA\&ID=78004. ACESSO EM: 07 MAI. 2019.

DREYFUS, Pablo. Vino Viejo em odres todavía más Viejos: Tendencias Regionales del Crimen Organizado em Latinoamérica em la primeira déCADA Del SIGLO XXI Y MÁS ALLÁ. IN:

ESPÓSITO NETO, TOMAZ; PAULA, O. F. Um BaLANço das ReLAções Brasileiro-Paraguaias nos Governos Lula/Dilma (2003-2012). In: THOMAZ, Laís Fort;; MATHIAS, Suzeley Kalit; OliVEIRA, Marcelo Fernandes. (Org.). Diálogos sul-americanos: 10 anos da política exteriOR. 1 ed. Marília: Editora Cultura Acadêmica, 2015, v. 1, p. 211-247. MAthieu, hans; ARRedondo, Paula Rodríguez (Eds.). Anuario 2009 de la Seguridad Regional em América Latina y el Caribe. Bogotá, 2009. ESCRITÓRIO DAS NAÇÕES UNIDAS SOBRE DROGAS E CRIME UnOdC. The Globalization of Crime: A Transnational Organized Crime Threat Assessment. Viena, 2010. Disponível em: https://WwW.unodC.org/ DOCUMENTS/DATA-AND-ANALYSIS/TOCTA/TOCTA_REPORT_2010_LOW_RES.PDF. ACESSO EM: 17 JUL. 2019. 
Cooperação Militar contra o Crime Organizado: Brasil e Paraguai no combate... Marcos Alan S. V. Ferreira • Juliana Leite de Medeiros

ESCRITÓRIO DAS NAÇÕES UNIDAS SOBRE DROGAS E CRIME. World Drug Report 2013. Viena, 2013. Disponível em: https://www. UNODC.ORG/UNODC/SECURED/WDR/WDR2013/WORLD_DRUG_REPORT_2013.PDF. ACESSO EM: 17 JUL. 2019.

Ferreira, Marcos Alan S. V. Criminality and Violence in South America: The Challenges for Peace and UNASUR's Response. International Studies Perspectives, v. 18, N. 1, 2017A, P. 64-80.

Ferreira, Marcos Alan S. V. Estudos Críticos da Paz e Crime Organizado Transnacional. Revista Crítica de Ciências Sociais, Lisboa, 2017B, p. 2950.

Ferreira, Marcos Alan S. V. Transnational Organized Crime and Structural Violence in Brazil. In: Atieno, C. e Robinson, C. Postconflict Security, Peace and Development. Cham: Springer, 2019.

GOTTSCHALK, P. 'Entrepreneurship In ORganised CRIME', INT. J.

Entrepreneurship and Small Business, Vol. 9, No. 3, pp.295-307, 2010.

HerZ, Monica. Concepts of Security in South America. International Peacekeeping, v. 17, N. 5, 2010, P. 598-612.

INSTITUTO DE ESTUDIOS COMPARADOS EM CIENCIAS PENALES Y SOCIALES DE PARAGUAY - INECIP. CRIMEN, PRISIÓN E INSEGURIdad. Elementos para el abordaje de la CRISIS. Assunção, 2016. Disponível EM: HTTP://INECIP.ORG.PY/WP-CONTENT/UPLOADS/2016/12/CRIMENPRISIO\%C3\%ACN-E-INSEGURIDAD.PDF. ACESSO EM: 01 JUN. 2019. INTERNATIONAL NARCOTICS CONTROL BOARD - INCB. REPORT OF the International Narcotics Control Board for 2012. Nova lorque, 2013. DisPoníVEL EM: HTTPS://WWW.INCB.ORG/DOCUMENTS/PUBLICATIONS/ AnnualReports/AR2012/AR_2012_E.PdF. Acesso em: 07 mal. 2019. INTERNATIONAL NARCOTICS CONTROL BOARD - INCB. REPORT OF the International Narcotics Control Board for 2015. Nova lorque, 
Cooperação Militar contra o Crime Organizado: Brasil e Paraguai no combate... Marcos Alan S. V. Ferreira • Juliana Leite de Medeiros

2016. Disponivel em: hTtPS://WWw.InCB.oRg/DOCUMEnts/Publications/ AnnualReports/AR2015/English/AR_2015_E.PDF. Acesso em: 07 MAl. 2019. JORNAL DO BRASIL. O Brasil prepara a sua defEsa. 18 nov. 2012. DISPONIVEL EM: HTTP://WWW.JB.COM.BR/PAIS/NOTICIAS/2012/11/18/O-BRASIL-PREpara-A-SUA-DEFESA/. Acesso em: 07 mal. 2019.

KACOWICZ, ARIE. Zones of Peace in the Third World: South America and West Africa in Comparative Perspective. Albany, NY: State University of New York Press, 2018.

LANDim, Hiarlley Gonçalves Cruz. Sisfron: Ferramenta de ampliação da diplomacia militar brasileira e fortalecimento do CDS. Rev. Política Hoje, V. 24, 2015, P. $135-147$.

MACHADO, Lia Osório. Limites, Fronteiras, Redes. In: STROHAECKER, Tânia Marques et al. (Orgs.). Fronteiras e Espaço Global. AGB - Porto Alegre: Porto Alegre, 1998.

MATHIAS, Suzeley; GUZZI, André. Novas ameaças na América do Sul: o papel do Brasil no caminho da cooperação em Defesa e Segurança.

\section{Conferência Conjunta International Studies Association - Associação} Brasileira de Relações Internacionais. Rio de Janeiro: 2009. Disponível EM: HTTP://CITATION.ALLACADEMIC.COM//META/P_MLA_APA_RESEARCH_CITATION/3/8/1/3/1/PAGES381316/P381316-1. PHP. ACESSO EM: 07 MAl. 2019.

mugGaH, Robert; Diniz, Gustavo. Protegendo as Fronteiras: o Brasil e

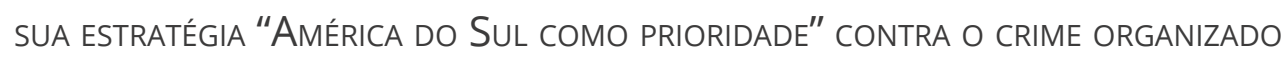
transnaCional. Instituto Igarapé. 2013. Disponível em: htTPS://publicacoes. IGARAPE.ORG.BR/PROTEGENDO-AS-FRONTEIRAS-O-BRASIL-E-SUA-ESTRATEGIA-AMERICA-DO-SUL-COMO-PRIORIDADE-CONTRA-O-CRIME-ORGANIZADO-TRANSNACIONAL/. ACESSO EM: 07 MAI. 2019.

NAIM, Moisés. llícito: o ataque da pirataria, da laVAGem de dinheiro e do TRÁFICO À ECONOMIA GLOBAL. RIo de JANeIRo: Zahar, 2006.

OBOKata, Tom. Transnational Organised Crime in International Law. HaRt Publishing: PortLand, 2010. 
Cooperação Militar contra o Crime Organizado: Brasil e Paraguai no combate... Marcos Alan S. V. Ferreira • Juliana Leite de Medeiros

Oliveira, Emmanuel Nunes de; MARTinS, João Henrique. Globalização e mercados transnacionais ilícitos na América Latina. Conexão Política, TERESINA, v. 3, N. 2, P. 11-26, AGo./DEZ. 2014.

OLiVeira, Márcio Gimene de. A Fronteira Brasil-Paragual: principais FATORES DE TENSÃO DO PERÍODO COLONIAL ATÉ A ATUALIDADE. 2008. 110 P. Dissertação (Mestrado) - Departamento de Geografia. Universidade de Brasília, Brasília, 2008.

ORGANIZAÇÃO DOS ESTADOS AMERICANOS - OEA.

Declaração sobre segurança nas Américas. Cidade do México, 2003. DISPONÍVEL EM: HTTP://WWW.DIREITOSHUMANOS.USP.BR/INDEX.PHP/OEAOrganiza\%C3\%A7\%C3\%A3o-dOS-Estados-Americanos/deCLARACAO-SOBRE-SEgURANCA-NAS-AMERICAS.HTML. ACESSO em: 07 MAI. 2019.

ORGANIZAÇÃO DAS NAÇÕES UNIDAS - ONU. A MORE SECURE WORLD: our shared resposibility. Report of the High-leVel Panel on Threats, Challenges and Change. 2004. Disponível em: http://Www.un.org/en/ EVENTS/PASTEVENTS/A_MORE_SECURE_WORLD.SHTML. ACESSO EM: 07 MAI. 2019. Pereira, Paulo José dos Reis. Crime Transnacional na América do Sul: IDENTIFICAÇÃo e COMBate. $4^{\circ}$ Encontro Nacional da Associação Brasileira de Relações Internacionais. Belo Horizonte: 2013. Disponível em: HTTP://WWW.ENCONTRONACIONAL2013.ABRI.ORG.BR/ARQUIVO/DOWNLOAD?ID_ ARQUIVO=2739. ACESSO EM: 07 MAI. 2019.

ReZende, lucas Pereira. Sobe e desce! Explicando a cooperação em defesa na América do Sul: uma teoria Realista-ofensiva. Brasília: Ed. UNB, 2015.

RODER, Ariane. A agenda externa brasileira em face aos ilícitos internacionais: o contrabando na fronteira entre Brasil e Paragual. 2009. 107 f. Dissertação (Mestrado em Ciência Política) - Universidade de São Paulo USP. 
Cooperação Militar contra o Crime Organizado: Brasil e Paraguai no combate... Marcos Alan S. V. Ferreira • Juliana Leite de Medeiros

SCHERMA, Márcio Augusto. Políticas de Defesa e Segurança para as Fronteiras nos Governos lula e Dilma. In: Boletim de Economia e Política INTERNACIONAL (BEPI), N. 22, P. 65-77. JAN./ABR., 2016. DisPONÍVEL EM: HTTP://WWW.IPEA.GOV.BR/PORTAL/IMAGES/STORIES/PDFS/BOLETIM_INTERNACIONAL/160628_BOLETIM_INTERNACIONAL_22_ART05.PDF. ACESSO EM: 01 ABR. 2019.

SilVa, Ana Regina Ferreira da. Perspectivas das políticas territoriais na FAIXA DE FRONTEIRA INTERNACIONAL DA AMAZÔNIA ORIENTAL BRASILEIRA: ESTADOS do Pará e do Amapá. 2011. 190 f. Dissertação (Mestrado em Geografia) Universidade Federal do Pará, Belém, 2011.

SilVA, Caroline Cordeiro Viana e. Segurança internacional e novas AMEAÇAS: A SECURITIZAÇÃO DO NARCOTRÁFICO NA FRONTEIRA BRASILEIRA. 2013. 126f. Dissertação (Mestrado em Ciência Política) - Setor de Ciências Humana, letras e Artes, Universidade Federal do Paraná, Curitiba, 2013.

TANNO, Grace. A contribuição da escola de Copenhague aos estudos de segurança internacional. Contexto int., Rio de Janeiro, v. 25, N. 1, P. 47-80, JUNE 2003. DISPONÍVEL EM HTTP://WWW.SCIELO.BR/SCIELO.PHP?SCRIPT=SCI_ARTTEXT\&PID=S0102-85292003000100002\&LNG=EN\&NRM=ISO. ACESSO EM: 07 MAI. 2019.

\section{UNIÃO EUROPÉIA - UE. Relatório sobre a Execução da Estratégia}

Europeia de Segurança: Garantir a Segurança num Mundo em Mudança. BRUXELAS, 2008. DISPONIVEL EM: HTTP://WWW.CONSILIUM.EUROPA.EU/UEDOCS/CMS_ DATA/DOCS/PRESSDATA/PT/REPORTS/104638.PDF. ACESSO EM: 07 MAI. 2019.

Vieira, Marcelo Milano Falcão; Vieira, Eurípedes Falcão. Geoestratégia GLOBAL: ECONOMIA, PODER E GESTÃo DE TERRITÓRIOS. RIO DE JANEIRO: EDITORA FGV, 2007.

ViZentini, Paulo Fagundes. Brasil: Problemas de defesa e segurança no SÉCULO XXI. IN: O Brasil No CENÁRIO INTERNACIONAL DE DEFESA E SEGURANÇa. Brasília: Ministério da Defesa, Secretaria de Estudos e de Cooperação, 2004. 
Cooperação Militar contra o Crime Organizado: Brasil e Paraguai no combate... Marcos Alan S. V. Ferreira • Juliana Leite de Medeiros

WiLliamS, Phil. Crime, Illicit Markets, and Money Laundering. IN SiMMONS, P.j.; OUdRAAT, Chantal de Jonge (eds.). Managing

Global Issues: Lessons Learned (pp. 106-150). Carnegie Endowment for International Peace: Washington, 2001. Disponível em: http://CarnegieenDOWMENT.ORG/PDF/FILES/MGI-CH3.PDF. ACESSO EM: 07 MAI. 2019.

Zabyelina, Yuliva. Transnational Organized Crime in International Relations. Central European Journal of International and Security Studies: Praga, v. 3, N. 1, 2009. Disponível EM: htTP://www.Cejiss.org/ISSUE-DETAIL/TRANSNATIONAL-ORGANIZED-CRIME-IN-INTERNATIONAL-RELATIONS. ACESSO EM: 07 MAI. 2019. 